\title{
REKAYASA SISTEM PENGIRIMAN INFORMASI JANGKAUAN LAN DAN WAN TVRI JAWA TENGAH MENGGUNAKAN SERVER SAMBA DAN FTP
}

\author{
Alfian Hidayat $^{1}$, Hery Mustofa ${ }^{2}$, Stefanus Widhiatmoko $^{3}$ \\ ${ }^{12}$ UIN Walisongo Semarang \\ ${ }^{3}$ TVRI Jawa Tengah \\ alfianhidayat_1808096025@student.walisongo.ac.id, \\ herymustofa@walisongo.ac.id, \\ jatengtvri@gmail.com
}

\begin{abstract}
Information delivery is a vital object for the Central Java TVRI public broadcasting institution (LPP), because the overall activity that occurs at Central Java TVRI LPP is the delivery of information. LPP TVRI Central Java requires updated information from regional correspondents so that the content broadcast by TVRI Central Java is always fresh and viewers get the latest information. The different locations of correspondents and different delivery methods are a challenge for sending information to the TVRI editorial office in Central Java. For this reason, it is necessary to create an effective and efficient internalexternal information delivery system for TVRI Central Java using FTP Server and Samba Server. It is proven that the file size of $125 \mathrm{MB}$ can be transferred in 40 seconds and a speed of 2.2. Mb/s with successful/OK status.
\end{abstract}

Keywords: Server, FTP, Protocol

\begin{abstract}
Abstrak
Pengiriman Informasi merupakan objek vital bagi lembaga penyiaran public (LPP) TVRI Jawa Tengah, pasalnya keseluruhan aktivitas yang terjadi pada LPP TVRI Jawa Tengah adalah pengiriman informasi. LPP TVRI Jawa Tengah membutuhkan informasi terupdate dari koresponden-koresponden daerah agar konten yang ditayangkan TVRI Jawa Tengah selalu segar dan penonton mendapatkan informasi terbaru. Lokasi-lokasi koresponden yang berbeda dan metode pengiriman yang berbeda menjadi tantangan tersendiri untuk pengiriman informasi ke redaksi TVRI Jawa Tengah. Untuk itu, perlunya dibuatkan sebuah sistem pengiriman informasi internal-eksternal TVRI Jawa Tengah yang efektif dan efisien menggunakan Server FTP dan Server Samba. Terbukti besaran file 125 MB dapat di transfer dengan waktu 40 detik dan kecepatan 2.2. Mb/s dengan status berhasil/OK.
\end{abstract}

Kata kunci : Server, FTP, Protokol 


\section{PENDAHULUAN}

Pengiriman Informasi merupakan objek vital bagi lembaga penyiaran publik(LPP) TVRI Jawa Tengah, pasalnya keseluruhan aktivitas yang terjadi pada LPP TVRI Jawa Tengah adalah pengiriman informasi. LPP TVRI Jawa Tengah membutuhkan informasi terupdate dari ko-respondenkoresponden daerah agar konten yang ditayangkan TVRI Jawa Tengah selalu segar dan penonton mendapatkan informasi terbaru. Lokasi-lokasi koresponden yang berbeda dan metode pengiriman yang berbeda menjadi tantangan tersendiri untuk pengiriman informasi ke redaksi TVRI Jawa Tengah, selain itu, jaringan internal TVRI Jawa Tengah pun harus saling terkoneksi satu sama lain agar perwakilan tiap-tiap bidang operasional yang berada di TVRI Jawa Tengah tidak harus berlari membawa hard disk drive (HDD) untuk menyalin sebuah file dari bidang satu ke bidang lain. Untuk itu, perlunya dibuatkan sebuah sistem pengiriman informasi internal-eksternal TVRI Jawa Tengah yang efektif dan efisien. Pada penelitian ini, sistem pe-ngiriman informasi menggunakan Server FTP dan Server Samba.

\section{METODE}

Pembuatan sistem pengiriman informasi menggunakan metode waterfall, dengan teknik Pengumpulan data meliputi: pengamatan (observation), wawancara (interview) dan kepustakaan (literature). Tahapan pembuatan sistem sebagai berikut:

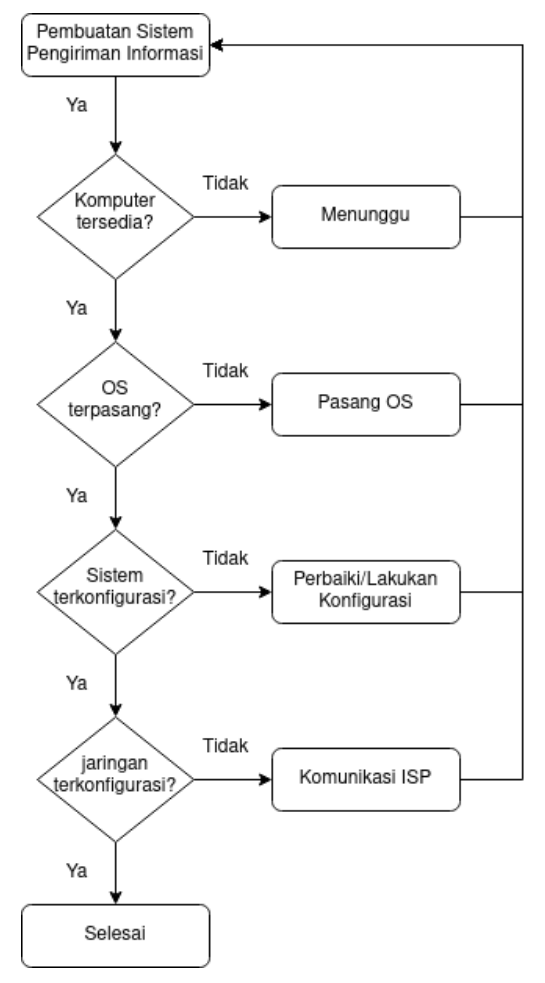

Gambar 1. Tahapan Pembuatan Sistem Pengiriman Informasi 


\section{KERANGKA TEORI}

Sistem adalah sebuah tatanan (keterpaduan) yang terdiri atas sejumlah komponen fungsional (dengan satuan fungsi dan tugas khusus) yang saling berhubungan dan secara bersama-sama bertujuan untuk memenuhi suatu proses tertentu. (Fatansyah, 2016)

Pengiriman Informasi merupakan kegiatan mengirim-kan informasi, pada konteks server informasi berbentuk digital dan lebih umum dikenal dengan sebutan berkas/file.FTP merupakan salah satu protokol internet yang paling awal dikembangkan, dan masih digunakan hingga saat ini untuk melakukan unduh atau unggah data. Sebuah klien FTP merupakan aplikasi yang dapat mengirimkan perintah FTP ke server FTP, sementara server FTP adalah sebuah Windows Service (OS windows) atau daemon (OS selain windows) yang aktif di komputer dan melakukan respon perintah dari klien FTP. Perintah-perintah FTP dapat digunakan untuk mengubah direktori, mengubah hak akses file, mengunduh ataupun mengunggah dari server FTP. FTP menggunakan Protokol Transmission Control Protocol (TCP) untuk komunikasi data antara klien dan Server, sehingga di antara kedua komponen tersebut akan dibuatlah sebuah sesi komunikasi sebelum pengiriman data dimulai. Sebelum membuat koneksi, port TCP nomor 21 di sisi server akan "mendengarkan" percobaan koneksi dari sebuah FTP klien dan kemudian akan digunakan sebagai port pengatur (Control Port) untuk (1) membuat sebuah koneksi antara klien dan server, (2) untuk mengijinkan klien untuk mengirimkan sebuah perintah FTP kepada server dan juga (3) mengembalikan respons server ke perintah tersebut. Sekali koneksi control telah dibuat, maka server akan mulai membuka port TCP nomor 20 untuk membentuk sebuah koneksi baru dengan klien untuk mengirim data aktual yang sedang dipertukarkan saat me-lakukan pengunduhan dan pengunggahan. (Kurniawan, 2017)

Samba adalah program yang dapat menjembatani kompleksitas berbagai platform system operasi Linux (UNIX) dengan mesin Windows yang dijalankan dalam suatu jaringan komputer. Samba merupakan aplikasi dari UNIX dan Linux, yang dikenal dengan SMB (Service Message Block) protokol. (Rahmayani, 2020)

\section{HASIL DAN PEMBAHASAN}

Membangun sebuah sistem pengiriman informasi berarti membuat sebuah mekanisme bagaimana pihakpihak berwenang saling dapat bertukar informasi. Hal-hal yang dibutuhkan untuk membuat sebuah sistem pengiriman informasi antara lain:

\subsection{MEDIA PENGIRIMAN INFORMASI}

Media pengiriman informasi berupa komputer server dengan spesifikasi sebagai berikut: 
Rekayasa Sistem Pengiriman Informasi Jangkauan LAN dan WAN TVRI Jawa Tengah Menggunakan Server Samba dan FTP

Tabel 1. Spesifikasi Komputer Server

\begin{tabular}{|c|l|c|}
\hline No & \multicolumn{1}{|c|}{ NAMA BARANG } & JUMLAH \\
\hline 1. & AMD RYZEN 7 5800X & 1 \\
\hline 2. & MOTHERBOARD MSI B550-A PRO & 1 \\
\hline 3. & RAM TEAM TCreate Classic 32GB - 2x16GB & 1 \\
\hline 4. & EKWB AIO BASIC 240 Liquid Water Cooling & 1 \\
\hline 5. & Storage WD BlackSN850 M.2 Pcie Gen4 Nvme 2280 1TB & 1 \\
\hline 6. & Patriot Viper VP4100 M.2 2280 PCIe Gen4 x4 1TB & 1 \\
\hline 7. & WD Blue SSD 3D Nand2TB Sata3 - 2.5" & 1 \\
\hline 8. & LEADTEK NVIDIA QUADRO P620 2GB & 1 \\
\hline 9. & Display Asus-VP228H & 1 \\
\hline 10. & keyboard / Mouse Logitech - MK120 & 1 \\
\hline 11. & Casing Zalman Z9 Neo Black ATX & 1 \\
\hline 12. & Power Supply Deepcool PSU 750W - DQ750ST80+Gold & \\
\hline 13. & Konektor RJ 45 CAT 6 (100 pcs) & \\
\hline 14. & VGA Asus Geforce GT710 2GB DDR5 & 1 \\
\hline
\end{tabular}


Topologi jaringan TVRI Jawa Tengah menggunakan topologi tree, sebuah topologi gabungan antara topologi star dan topologi bus. Topologi untuk komputer-komputer di ruang master control tempat server berada menggunakan topologi star dengan beberapa komputer terhubung ke gigabit ethernet switch keluar dari ruang master control ke ruang berita dan lainnya juga demikian, terdapat gigabit ethernet switch pada masingmasing ruangan yang semua komputer terhubung kesana. Semua konfigurasi jaringan meliputi IP dan routing ditangani pada router utama menggunakan mikrotik

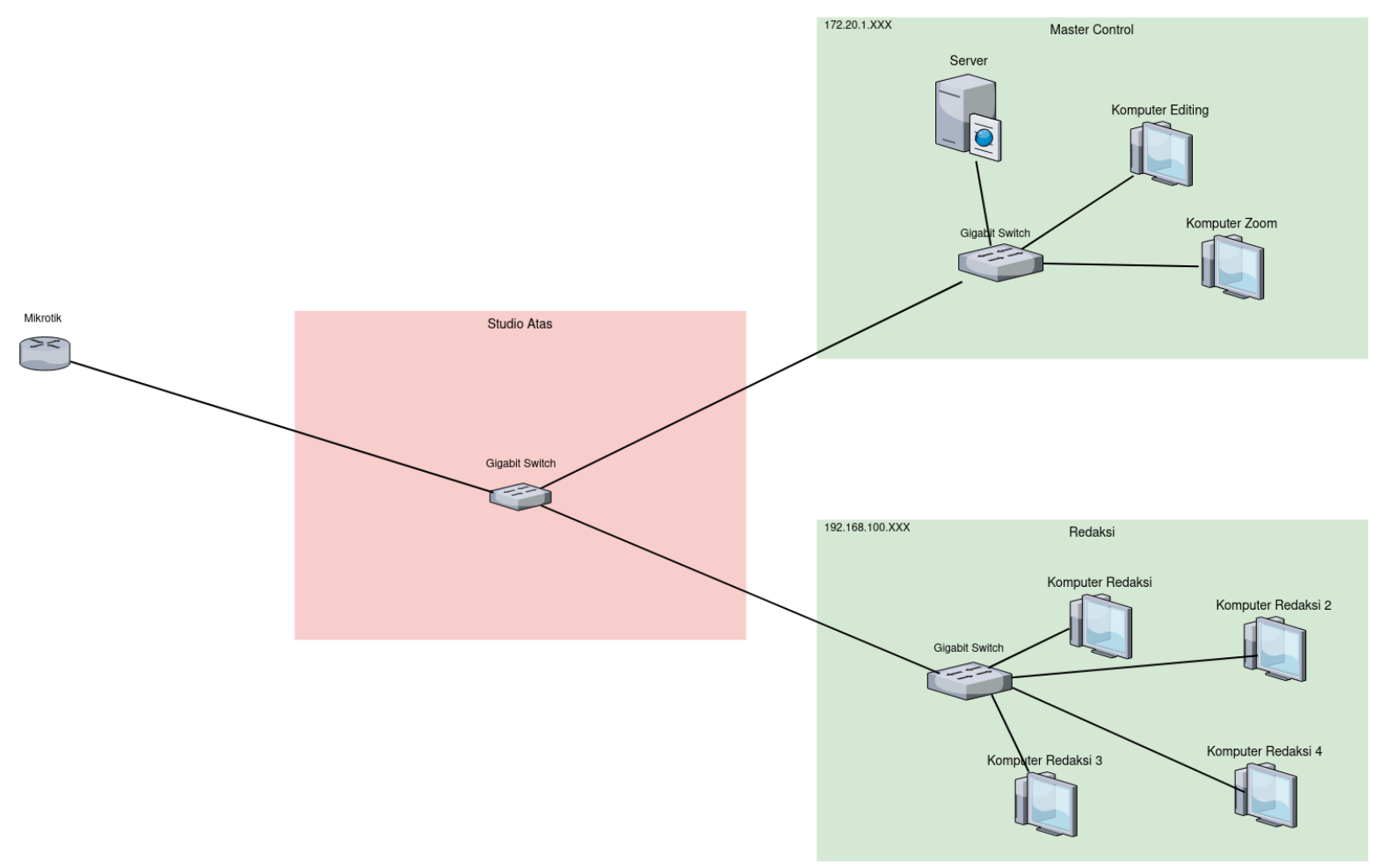

Gambar 2. Topologi Jaringan TVRI Jawa Tengah 
Komputer server menggunakan sistem operasi Linux Ubuntu, tahapan instalasi sistem operasi yaitu pertamatama membuat sebuah bootable usb, melakukan live usb boot dengan bootable usb yang sudah dibuat, selanjutnya mengikuti petunjuk instalasi menggunakan GUI(Graphical User Interface) installer.
Setelah sistem operasi terinstal, selanjutnya melakukan instalasi aplikasi yang dibutuhkan yaitu vsftpd untuk servis ftp dan samba untuk servis samba. Alasan menggunakan ftp dan samba karena lebih familiar dan mudah digunakan. Ftp dan samba memiliki kelebihan dan kekurangan sebagai berikut:

Tabel 2. Kelebihan dan Kekurangan FTP dan Samba

\begin{tabular}{|c|c|c|c|}
\hline No & Server & Kekurangan & Kelebihan \\
\hline 1 & Samba & $\begin{array}{l}\text { 1. Apabila digunakan keluar } \\
\text { localhost beresiko dengan } \\
\text { keamanan. } \\
\text { 2. Client harus berada dalam satu } \\
\text { subnet. }\end{array}$ & $\begin{array}{l}\text { 1. Cepat untuk jaringan area } \\
\text { lokal. } \\
\text { 2. Tidak membutuhkan } \\
\text { aplikasi tambahan sebagai } \\
\text { client karena sudah ada } \\
\text { pada bawaan windows. }\end{array}$ \\
\hline 2 & FTP & $\begin{array}{l}\text { 1. Membutuhkan aplikasi } \\
\text { tambahan bagi client. }\end{array}$ & $\begin{array}{l}\text { 1. Client tidak harus satu } \\
\text { subnet. } \\
\text { 2. Cepat dan dapat } \\
\text { diandalkan untuk jaringan } \\
\text { area lebar/internet. }\end{array}$ \\
\hline
\end{tabular}


Linux Ubuntu dibekali dengan manajer paket apt, jadi untuk melakukan instalasi kedua aplikasi tersebut relatif mudah, perintah-perintahnya sebagai berikut:

\$ sudo su (ini digunakan untuk melakukan operasi perintah dalam sistem operasi sebagai user root atau superuser, selain mendapatkan akses penuh, hal ini dilakukan agar tidak menggunakan perintah sudo pada tiap-tiap perintah berikutnya, dan mengubah simbol \$ menjadi \#)

\# apt update \&\& apt upgrade (rogerpack2005, 2015)

\# apt install vsftpd samba (rogerpack2005, 2015)

Setelah aplikasi vsftpd dan samba terinstal, selanjutnya dilakukan konfigurasi pada aplikasi tersebut, data konfigurasi berada di direktori letc/vsftpd.conf dan /etc/samba/smb.conf dengan isi sebagai berikut:

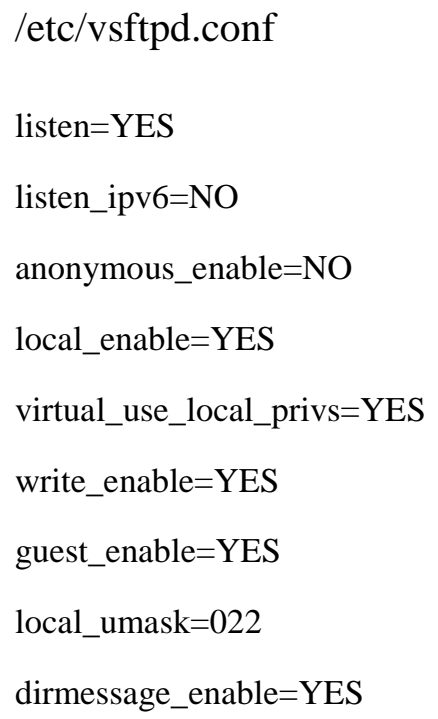

WJIT_:Walisongo Journal of Information Technology - Vol. 3, No. 2 (2021) use_localtime $=$ YES

xferlog_enable $=$ YES

connect_from_port_20=YES

xferlog_file=/var/log/vsftpd.log

ftpd_banner=Welcome to TVRI JATENG FTP service.

hide_ids=YES

user_sub_token=\$USER

user_config_dir=/etc/vsftpd/user_conf

chroot_local_user=YES

allow_writeable_chroot=YES

secure_chroot_dir=/var/run/vsftpd/empty

pam_service_name $=$ vsftpd

rsa_cert_file=/etc/ssl/private/vsftpd.pem

rsa_private_key_file=/etc/ssl/private/vsftpd .pem

pasv_enable=YES

pasv_min_port $=40000$

pasv_max_port $=50000$

pasv_promiscuous $=$ YES

userlist_enable=YES

userlist_file=/etc/vsftpd/userlist

userlist_deny=NO

ssl_enable $=$ YES

ssl_tlsv1=YES

ssl_sslv2=NO

ssl_sslv3=NO

force_local_logins_ssl=NO

force_local_data_ssl=NO

utf8_filesystem=YES

/etc/ samba/smb.conf 
[global]

workgroup $=$ WORKGROUP

netbios name $=$ FTPSERVER

lanman auth $=$ no

ntlm auth $=$ yes

wins support $=$ yes

local master $=$ yes

preferred master $=$ yes

server string $=\%$ h server $($ Samba,

Ubuntu)

$\log$ file $=/$ var $/ \log / \mathrm{samba} / \log . \% \mathrm{~m}$

$\max \log$ size $=1000$

$\operatorname{logging}=$ file

server role $=$ standalone server

obey pam restrictions $=$ yes

unix password sync $=$ yes

pam password change $=$ yes

map to guest $=$ bad user

usershare allow guests $=$ yes

hosts allow $=127.172 .192$.

[ftp]

comment $=\mathrm{ftp}$ share

valid users $=$ redaksi

path $=/$ srv/ftp $/$

browsable $=$ yes

writable $=$ yes

read only $=$ no

guest ok $=$ no

[Media Sharing Center]

comment $=$ Samba Files

valid users $=$ redaksi

path $=/$ srv/mediasharingcenter browsable =yes

writable $=$ yes

read only $=$ no

guest ok $=$ no

Tahapan berikutnya yaitu menjalankan servis daemon yaitu sebuah servis yang berjalan di belakang layar dan otomatis berjalan ketika sistem operasi berjalan, jadi ketika komputer restart, tidak diperlukan tindakan manual untuk menjalankan aplikasi vsftpd dan samba tersebut. Perintahnya sebagai berikut:

\# systemctl start $\{$ vsftpd,smbd $\& \&$ systemctl enable $\{$ vsftpd, smbd $\}$

Langkah terakhir yaitu konfigurasi jaringan, untuk konfigurasi jaringan lokal, server hanya dilakukan konfigurasi pada IP statis 172.20.1.30, untuk dapat digunakan ke eksternal atau internet, maka dilakukan konfigurasi IP statis lokal ke IP statis publik dan melakukan portforwarding, dikarenakan seluruh jaringan yang berada di TVRI Jawa Tengah dimanajemeni oleh ISP, jadi pihak TVRI Jawa Tengah hanya mengkomunikasikan konfigurasinya, dan pihak ISP yang melakukannya.

\subsection{Aturan/Protokol}

Aturan atau protokol berupa SOP tentang bagaimana cara bertukar informasi dengan media pengiriman informasi yang telah dibuat. Hal ini dibagi menjadi dua yang pertama sisi server dan client. Server menggunakan protokol ftp dengan aplikasi vsftpd dan 
smb dengan aplikasi samba. Client menggunakan aplikasi Filezilla atau FTP Client yang dapat digunakan untuk mengakses server FTP, sedangkan Samba dapat menggunakan File Explorer Windows ataupun File Explorer sistem operasi lainnya seperti linux. (Nugroho \& Hadrianto, 2016, 13)
Setelah media pengiriman informasi berhasil dibuat dan dikonfigurasi dengan benar serta sudah dilakukan sosialisasi penggunaannya, maka sistem pengiriman informasi dapat digunakan. Berikut adalah gambaran ketika sistem pengiriman informasi sudah dapat digunakan:

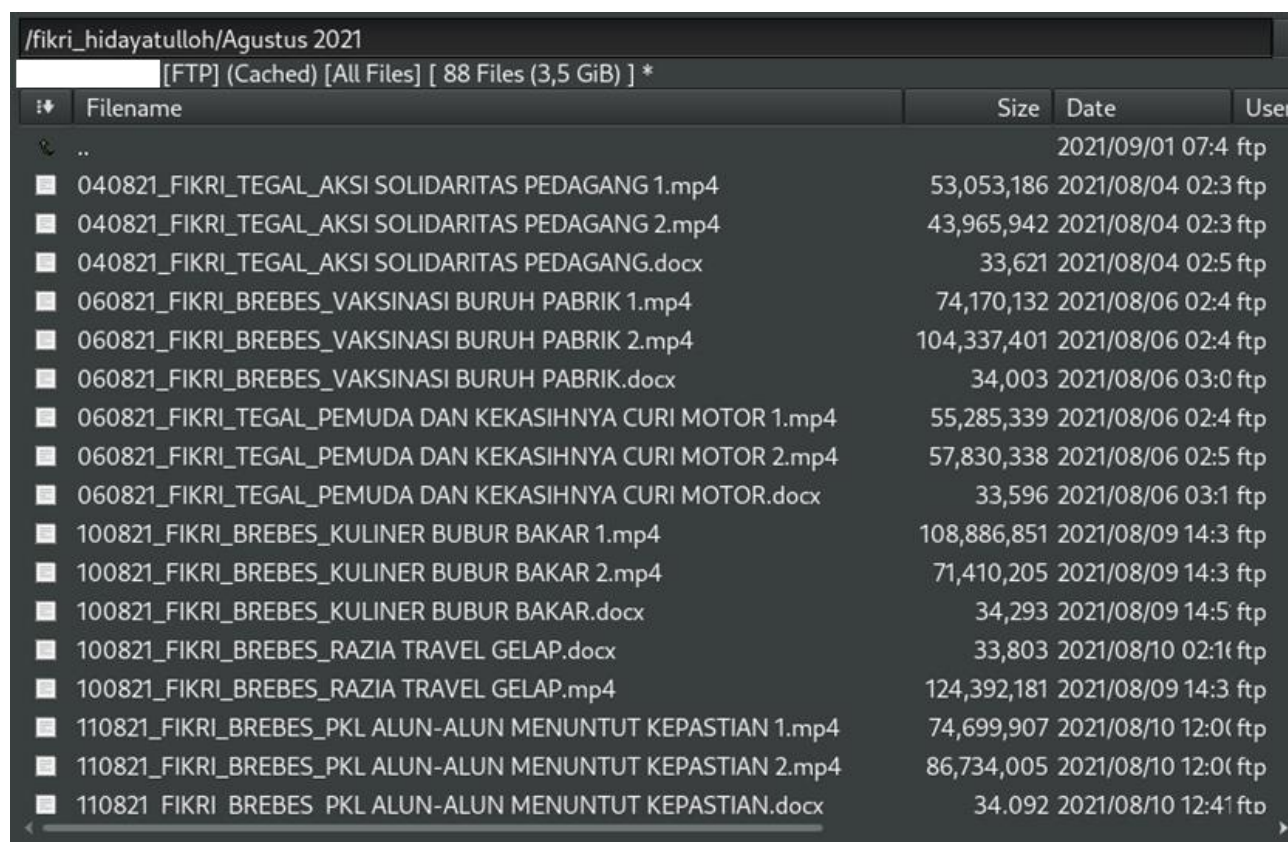

Gambar 3. Sistem Digunakan

Uji coba pada sistem mendapatkan data sebagai berikut:

Tabel 3. Uji Coba Sistem

\begin{tabular}{|c|l|c|c|l|}
\hline No & \multicolumn{1}{|c|}{ Kecepatan } & Besaran File & Status & \multicolumn{1}{|c|}{ Estimasi Waktu } \\
\hline 1 & $100 \mathrm{~KB} / \mathrm{s}$ & $10 \mathrm{MB}$ & OK & 58 detik \\
\hline 2 & $1 \mathrm{MB} / \mathrm{s}$ & $100 \mathrm{MB}$ & OK & 1 menit 38 detik \\
\hline 3 & $2.2 \mathrm{MB} / \mathrm{s}$ & $125 \mathrm{MB}$ & OK & 40 detik \\
\hline
\end{tabular}

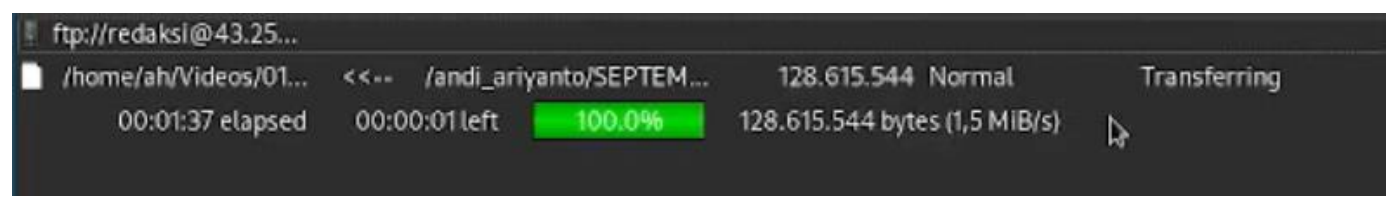

Gambar 4. Uji Coba Sistem

WJIT_:Walisongo Journal of Information Technology - Vol. 3, No. 2 (2021) 


\section{KESIMPULAN}

FTP dan Samba menyelesaikan persoalan pengiriman informasi yang tidak standar. Koresponden mengirim dan Redaksi mengambil pada satu komputer server yang berada di kantor operasional pucanggading, sehingga tidak ada latensi tambahan harus berputar ke Gombel. Terbukti besaran file $125 \mathrm{MB}$ dapat di transfer dengan waktu 40 detik dan kecepatan 2.2. $\mathrm{Mb} / \mathrm{s}$ dengan status berhasil/OK. Selain itu FTP dan Samba penggunaannya dapat dikembangkan lagi menjadi sebuah Media Sharing Center dimana tidak hanya bidang operasional yang dapat bertukar informasi namun seluruh bidang diberi akses untuk saling bertukar informasi pada server yang tersentral. 


\section{REFERENCE}

Arumaningrum, d. g. (2014). Implementasi ftp server dan monitoring client menggunakan mikrotik pada ubuntu 10.4. Lincolin Arsyad, 3(2), 1-46.

Fatulloh, A., \& Fauzan, I. (2020). Implementasi Active Directory Berbasis Open Source. JURNAL BIT (Budi Luhur Information Technology), 17(2), 33-39.

juki. (2017). Implementasi Protokol Ftp (File Transfer Protokol) Pada Kantor Kecamatan Lubuklinggau Utara I Sebagai Media Penyimpanan Jaringan. 549(1), 40-42.

Kurniawan, B., \& Herryanto, D. (2017). Perancangan Dan Implementasi Data Center Menggunakan File Transfer Protocol (Ftp). Jurnal Sistem Komputer Musirawas, 2(2), 91-97.

Nugroho, A., \& Hadrianto, Y. (2016). File Sharing Server Menggunakan Samba Server Dan Linux Ubuntu 12.04 Server. Paradigma - Jurnal Komputer dan Informatika, 18(2), 11-17. 10.31294/p.v18i2.1177

Nur, M. (2020). Implementasi Tentang Ftp Server. 10.31219/osf.io/7n6h5

Oklilas A. \& Irawan, B. (2014). Implementasi FTP Server Dengan Metode Transfer Layer Security Untuk Keamanan Transfer Data Menggunakan CentOS 5.8. Jurnal Generic, 9(2), 348-355.

PD, I. I. (2010). Perbandingan Penggunaan File Sharing Antara Pidgin Dengan Samba. Jurnal Teknologi, 3(1), 39-43.

Prabowo, D., Hidayat, A., \& Saputra, I. P. (2020). Implementasi Samba Server untuk Sharing Data Center pada Lab Komputer Universitas Muhammadiyah Metro. Jurnal Teknik Informatika Unika St. Thomas (JTIUST), 5.

Rahmayani, S. N., Maylane, A. B., \& Darpono, R. (2020). Konfigurasi Sharing File Menggunakan Samba Server Berbasis. (9).

Ramadhan, N. F. (2015). Analisis Penerapan File Sharing Terpusat Pada Perusahaan PT . Lumbung Riang. 5.

Sujana, A. P., \& Salam, M. (2018). Perancangan Dan Implementasi Ftp Server (Study Kasus : Prodi Teknik Komputer).

Sulistyo, H. W., \& Oktavianto, H. (2020). Perancangan Dan Implementasi File Sharing. Jurnal Aplikasi Sistem Informasi Dan Elektronika, 2(1), 24-30.

Wiyanti, D. T., Mubarok, D., \& Zahid, M. Z. (2018). File Sharing System Using Samba For Mathematics Laboratory. Jurnal Transformatika, 15 (2), 114. 10.26623/transformatika.v15i2.759

Rogerpack 2005, r. (2015). vsftpd. https://help.ubuntu.com/community/vsftpd 